exposures 4.5 days, figures which are very similar to those in our published series $(11.7,6.7,4.6,5.3$ and 4.5 days respectively). We excluded from our analysis one patient found at necropsy to have a carcinoma of the bile duct and another with abnormal liver function tests who did not actually become jaundiced. More than 25 further cases were reported or followed up too late for inclusion in the analysis.

Dr. M. H. M. Dykes and his colleagues (30 Manch, p. 638) referred to our omission of details of statistical tests and to the "unquestioned qualifications of the statistical consultants available to the authors." It was preaisely because of the latter and because all the data were displayed in our paper that we did not burden readers with details of the numerous tests that were performed. A Mann-Whitney $U$ test on the pooled double- and triple-exposure groups compared with the single exposure groups gave a value (of $U$ ) such that the normal deviate (z) equalled $2.94(P=0.0016$, single-tailed). Several $t$-tests on the raw data and on various transformations of the data gave results which were consistent with the nonparametric test.

It is not possible to compare Professor Simpson's 175 post-halothane cases with our own series. Indeed, his letter suggests that the two series are not comparable in at least one important respect. The mortality of $10 \%$ in his series contrasts with the mortality of $51 \%$ in ours, suggesting that a relatively larger proportion of mild cases were included in his series. However, Professor Simpson's letter adds support to our conclusion that multiple exposures to halothane increase the risk of postoperative jaundice since only $15 \%$ of the patients in our series and $19 \%$ of the patients in Professor Simpson's series had developed jaundice after a single exposure to halothane.

Other correspondents have referred to the fact that the committee has received no reports of postoperative jaundice occurring in patients who had not received halothane as part of their anaesthetic. It is possible that anaesthetists may have neglected to report "non-halothane jaundice" and we have ourselves stressed that our data were probably highly selected. So far, however, no such reports have been received by the committee in the three months following the publication of our paper.

We have suggested that the reported death rate after multiple exposure to halothane within a period of one month was about 10 times the risk of death from infectious hepatitis among the general population in any one year. Since, however, the deaths of patients in our series occurred within two months of the most recent exposure to halothane, we may have presented an unduly optimistic comparison. The risk that a hypothetical "control" patient selected from the general population on the same day that a patient had been re-exposed to halothane would die from infectious hepatitis within a similar period could be over 60 times less than the risk to the patient re-anaesthetized with halothane.

None of your correspondents has denied the probable existence of "halothane hepatitis" as an unoommon complication of anaesthesia. Its real incidence remains to be determined and it is hoped that more complete reporting of jaundice following anaesthesia with any agent will clarify the situation.-We are, etc.,

W. H. W. INMAN

Committee on Safety of Medicines, ondon E.C.2

W. W. Mushin

Department of Anaesthetics

Welsh National School of Medicine, Cardifi

SIR,-The methods by which the Committee on Safety of Medicines collects information about events that are suspected of being due to the adverse effect of a drug are well known in the United Kingdom, but it is understandable that they should be less well known elsewhere. It may therefore be helpful if I answer briefly the questions asked by Dr. M. H. M. Dykes and his colleagues (30 March, p. 638) following Dr. W. H. W. Inman and Professor W. W. Mushin's paper (5 January, p. 5 ).

(1) In the United Kingdom reports are requested from all doctors and dentists who observe adverse effects in patients under their care, the Registrar-General, who recives reports of deaths attributed to the use of drugs, coroners, and the pharmaceutical industry.

(2) The amount of information routinely requested is specified on special reporting cards. I have sent one to Dr. Dykes and will be glad to provide copies for other doctors on request.

(3) The scientific staff of the committee examine and classify all reports individually. The action taken subsequently depends on the nature of the report. Validation of all reported drug reactions is not undertaken routinely, but additional information is sought about specific cases when new risks are suspected or old risks require to be evaluated. This may involve correspondence with the doctor who reported the effect or he may be visited by one of the 80 parttime medical officers who assist the committee in different parts of the country. A detailed study of a random sample of the reports has shown that they are made responsibly. 1

(4) It is impracticable to define "specific diagnostic criteria" before classifying a reaction as probably, or possibly, or not due to a particular drug. Firstly, the committee would have to adopt different criteria for each reaction. Secondly, reports are received from a wide variety of doctors practising under different conditions with different facilities. Thirdly and most importantly, it is impossible to formulate diagnostic criteria for a new reaction before it is recognized, and any attempt to do so would serve only to prevent the oommittee from alerting the profession to a previously unsuspected hazard.

More detailed accounts of the committee's adverse reactions system have been published elsewhere. ${ }^{2}$-I am, etc.,

David MANSEL-JONES

Committee on Safety of Medicines, Condon E.C.2

1 Inman, W. H. W., and Evans, D. A. P., British Medical fournal, 1972, 3, 746 .

2 McLachlan, G., ed., Portfolio for Health 2, p. 63. London, Oxford University Press, 1973.

World Health Organization, Technical Report
Series No. 498, P. 37. Geneva, WH.O., 1972.
Dangerous Patients

SIR,-The leading article (23 March, p. 527) under this head confuses the issue. The problem is not the law but the material provision. Fourteen years ago the British Medical Association ${ }^{1}$ together with other concerned bodies suggested remedies. To the present time little has been done despite the urgency of the problem, though it is understood that new and construative proposals along the lines previously recommended are imminent.

The special hospitals are out of date, overcrowded, too big, too centralized, too divorced from other types of provision. A number of smaller units with facilities for investigation and research and with closer links with the mental health service generally are needed, with regional affiliations. There is a need for development of forensic psychiatry, of relevant aspects of the social services, and of the penal system in close association. Present developments reduce the need for a clear distinction between the "criminal lunatic" and the "criminal." It is all too easy under the law as it exists to lock up anyone who is thought to be dangerous. Long before 1959 admissions to Rampton were commonly of patients who had made no court appearance but who were a trouble to manage in local hospitals. In section 97 of the Mental Health Act the phrase is "dangerous, violent or criminal." The main bar to admission to secure units is lack of space. The proposed "medium" security units might acoommodate some of those not meeding "maximum" security. But "medium" security implies adequate staffing. Meanwhile there seems no reason why, if prison conditions could be made suitable, some of those who are a continuing danger to society could not be more appropriately lodged there.-I am, etc.,

BRIAN KIRMAN

Queen Mary's Hospital for Children,

Carshalton, Surrey

1 British Medical fournal, Supplement, 1960, 2, 228.

SIR,-Your leading article (23 March, p. 527) raises a point of increasing importance at the present time. Is it not time that both psychiatrists and their patients realized that there are patients who require secure (locked ward) accommodation, not for punishment, as seems to be constantly implied, but because of the nature of their symptoms, which of course they cannot help.

I would have thought they were entitled to these facilities rather than being allowed out to commit crimes, be social pests in the community, or kill themselves.-I am, etc., Littlemore Hospital,

J. ELWES DUFFIELD

\section{Chronic Brucellosis}

SIR,-Your leading article (23 February, p. 299) needs the following comment. The statement that the examination of the patient's blood for brucella antibodies may lsad to the diagnosis is obviously correct, but the following remark that if the agglutination test, the mercaptoethanol test, the complement fixation test, and the antihuman globulin test are all negative the diagnosis 